\title{
Electronic Structure and Magnetic Properties of $\mathrm{La}_{1-x} \mathrm{Ce}_{x} \mathrm{~Pb}_{3}$ and $\mathrm{La}_{1-x} \mathrm{Pr}_{x} \mathrm{~Pb}_{3}$ Alloys
}

\author{
A. JEZIERSKI ${ }^{a, *}$, J. KACZKOWSKI $^{a}$ AND T. CICHOREK ${ }^{b}$ \\ ${ }^{a}$ Institute of Molecular Physics, Polish Academy of Sciences, M. Smoluchowskiego 17, 60-179 Poznań, Poland \\ ${ }^{b}$ Institute of Low Temperature and Structural Research, Polish Academy of Sciences, Okólna 2, 50-950 Wrocław, \\ Poland
}

(Received July 16, 2013; in final form October 31, 2013)

\begin{abstract}
The electronic structure and magnetic properties of $\mathrm{La}_{1-x} \mathrm{Ce}_{x} \mathrm{~Pb}_{3}$ and $\mathrm{La}_{1-x} \mathrm{Pr}_{x} \mathrm{~Pb}_{3}$ are studied using the spin-polarized relativistic Korringa-Kohn-Rostoker coherent potential approximation method within the local spin density approximation. The calculated density of states at the Fermi level increases with the increase of the concentration. The dependence of spin and orbital magnetic moments of $\mathrm{La}_{1-x} \mathrm{Ce}_{x} \mathrm{~Pb}_{3}$ and $\operatorname{La}_{1-x} \operatorname{Pr}_{x} \mathrm{~Pb}_{3}(0<$ $x<1$ ) on the concentration is also reported. The densities of states at the Fermi energy are dominated by $\mathrm{Ce}(\mathrm{Pr})$ $4 f_{5 / 2}$ and $4 f_{7 / 2}$ states.
\end{abstract}

DOI: $10.12693 /$ APhysPolA.125.111

PACS 71.20.-b, 71.20.Eh, 71.20.Gj, 75.20.Hr

\section{Introduction}

$\mathrm{CePb}_{3}$ and $\mathrm{PrPb}_{3}$ compounds have shown various interesting physical properties and they belong to the group of strongly correlated electron systems or heavy fermion systems. The electronic and magnetic properties of $\mathrm{REPb}_{3}(\mathrm{RE}=\mathrm{La}, \mathrm{Ce}, \mathrm{Pr})$ compounds were studied experimentally and theoretically in the last years [1-17]. These systems crystallize into $\mathrm{Cu}_{3} \mathrm{Au}$ cubic type structure (space group No. 221). Welsh et al. [1] reported the results of nuclear magnetic resonance of the influence of Ce and Gd impurities on the properties of $\mathrm{LaT}_{3}(\mathrm{~T}=$ $\mathrm{In}, \mathrm{Sn}, \mathrm{Pb})$. The suppression of the superconducting transition temperature by impurities was observed. From the temperature dependence of resistivity for $\mathrm{LaPb}_{3} \mathrm{Kle}-$ towski et al. [5] estimated the Debye temperature $\theta$ as $125 \mathrm{~K}$. Ebihara et al. [7] have found the phase diagrams of $\mathrm{CePb}_{3}$ and they observed three phases: antiferromagnetic, spin flop, and paramagnetic. The phase diagram and de Haas-van Alphen (dHvA) effect of $\mathrm{PrPb}_{3}$ under pressure was also studied by Endo et al. [9]. $\mathrm{CePb}_{3}$ is a heavy fermion compound with an antiferromagnetic transition at $1.1 \mathrm{~K}$.

The dHvA measurements [6] have shown that the topological features of the Fermi surfaces of $\mathrm{CePb}_{3}$ were similar to $\mathrm{LaPb}_{3}$ and $\mathrm{PrPb}_{3}$ compounds. The Fermi surfaces of $\mathrm{LaPb}_{3}$ and $\mathrm{PrPb}_{3}$ are almost spherical. Aoki et al. [6] have measured the specific heat in the temperature range of 0.2 to $70 \mathrm{~K}$. The similar results were reported by Morie et al. [12], but they had measured the temperature dependence of the specific heat of $\mathrm{PrPb}_{3}$ below $300 \mathrm{mK}$. They estimated the value of the electronic part of the $\gamma$ coefficient as $1.5 \mathrm{~J} /\left(\mathrm{mol} \mathrm{K}^{2}\right)$. The magnetic field dependence

\footnotetext{
*corresponding author; e-mail: jeziersk@ifmpan.poznan.pl
}

of the specific heat in $\mathrm{PrPb}_{3}$ up to $H=8 \mathrm{~T}$ were measured by Sato et al. [16]. Magnetism and superconductivity of the heavy fermion $\mathrm{CePb}_{3}$ were studied theoretically by Strange and Gyorffy [2]. The electronic density of states and the Fermi surfaces was calculated by using linear muffin-tin orbital (LMTO) method. The theoretical value of $\gamma$ coefficient was estimated as $16.7 \mathrm{~mJ} /\left(\mathrm{mol} \mathrm{K}^{2}\right)$. Muon Knight shift measurements [13] suggested a strong hybridization between $4 f$ electrons of $\mathrm{Pr}$ with conduction electrons. Han et al. [4] calculated the band $f$ hybridizations for $\mathrm{La}_{1-x} \mathrm{Ce}_{x} \mathrm{~T}_{3}(\mathrm{~T}=\mathrm{Pb}, \mathrm{In}, \mathrm{Sn}, \mathrm{Pd})$ using LMTO-ASA method. Recently Swetarekha Ram et al. [17] studied the electronic structure, the Fermi surfaces and the elastic properties of $\mathrm{LaPb}_{3}$ by FP-LAPW method. The interesting physical properties of $\mathrm{LaPb}_{3}$, $\mathrm{CePb}_{3}$ and $\mathrm{PrPb}_{3}$ compounds motivated us for study of the electronic and magnetic properties of the disordered $\mathrm{La}_{1-x} \mathrm{Pr}_{x} \mathrm{~Pb}_{3}$ and $\mathrm{La}_{1-x} \mathrm{Ce}_{x} \mathrm{~Pb}_{3}$ systems by using the spin-polarized relativistic Korringa-Kohn-Rostoker coherent potential approximation method (SPR-KKRCPA) $[18,19]$.

\section{Method of calculations}

The electronic and magnetic properties of $\mathrm{La}_{1-x} \mathrm{Ce}_{x} \mathrm{~Pb}_{3}$ and $\mathrm{La}_{1-x} \mathrm{Pr}_{x} \mathrm{~Pb}_{3}(0<x<1)$ alloys were calculated by SPR-KKR-CPA $[18,19]$. The exchange-correlation potential was assumed in the form proposed by Perdew and Wang [20]. We assumed the linear dependence of lattice parameters on the concentration (Fig. 1). For $\mathrm{LaPb}_{3}, \mathrm{PrPb}_{3}, \mathrm{CePb}_{3}$ we get: $a=4.904 \AA, 4.863 \AA$, and $4.873 \AA$, respectively. The self-consistent calculations were performed for $936 k$-points in the irreducible part of the Brillouin zone. The total energy was converged to $10^{-5}$ Ry. The magnetic moments were calculated in full relativistic mode. 


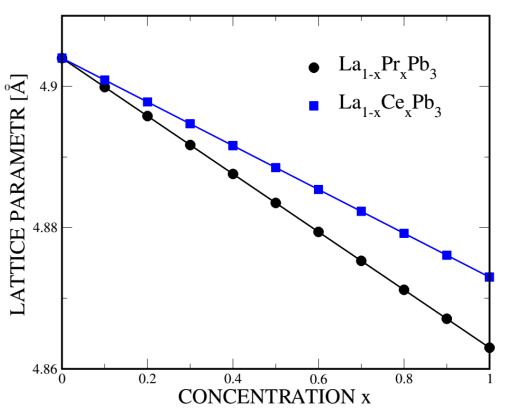

Fig. 1. The dependence of the lattice parameter on concentration $x$ for $\mathrm{La}_{1-x} \mathrm{RE}_{x} \mathrm{~Pb}_{3}, \mathrm{RE}=\operatorname{Pr}($ circle) and $\mathrm{RE}=\mathrm{Ce}$ (square).

\section{Results}

\subsection{Electronic densities of states of $L a_{1-x} C e_{x} P b_{3}$} and $L a_{1-x} P r_{x} P b_{3}$ alloys

The calculations were performed for the spin-polarized systems for the whole range of the concentration $(0<x<1.0)$. In Fig. 2a-e and Fig. 3a-e we present the total electronic densities of states (DOS) for spin

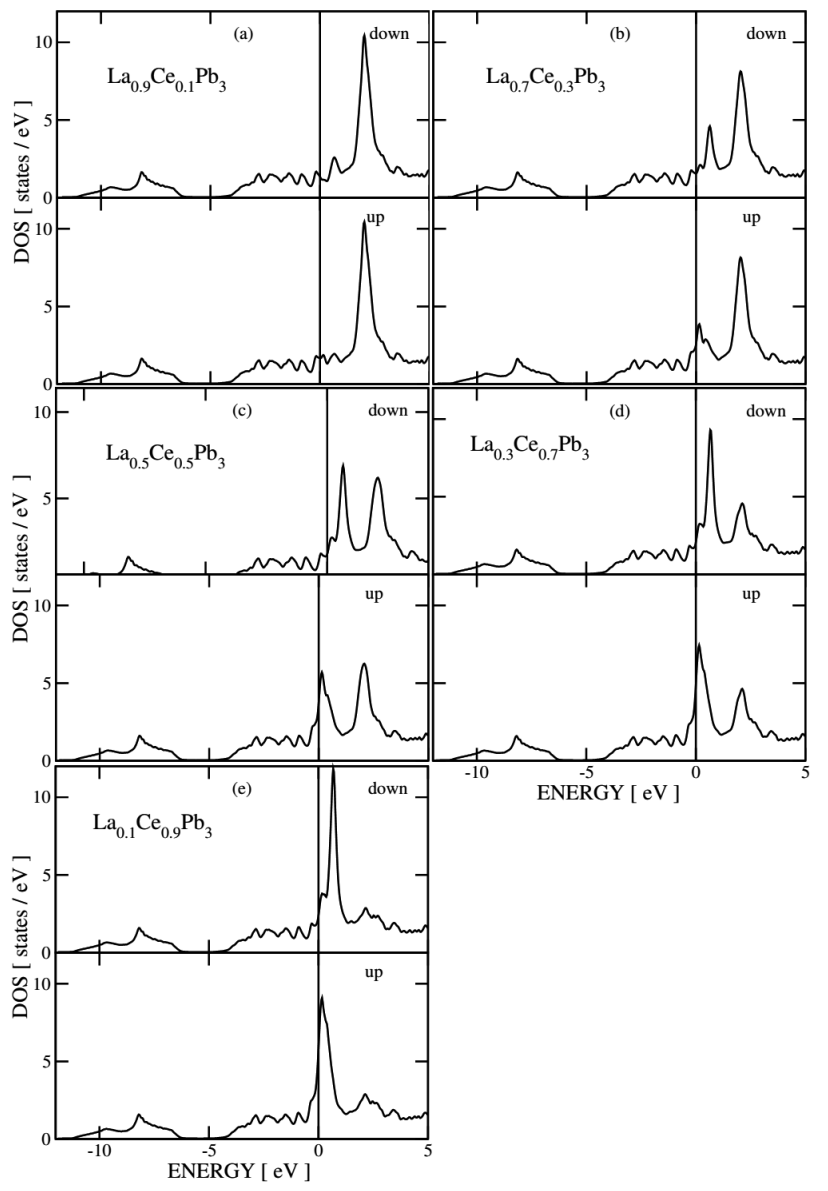

Fig. 2. Total density of states for $\mathrm{La}_{1-x} \mathrm{Ce}_{x} \mathrm{~Pb}_{3}$ for $x=0.1$ (a), 0.3 (b), 0.5 (c), 0.7 (d), and 0.9 (e). Upper part for minority spins, lower part for majority spins. The Fermi level is located at $E=0 \mathrm{eV}$.

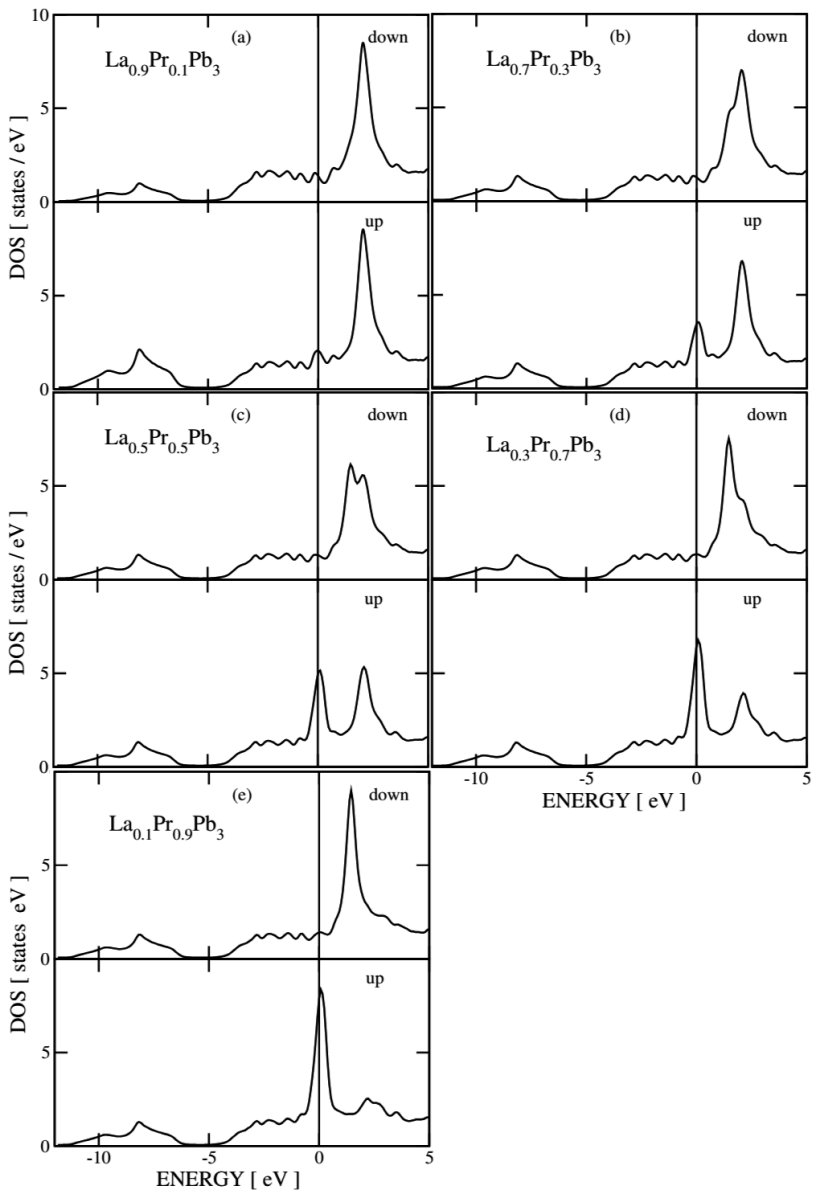

Fig. 3. Total density of states for $\mathrm{La}_{1-x} \operatorname{Pr}_{x} \mathrm{~Pb}_{3}$ for $x=$ 0.1 (a), 0.3 (b), 0.5 (c), 0.7 (d), and 0.9 (e). Upper part for minority spins, lower part for majority spins. The Fermi level is located at $E=0 \mathrm{eV}$.

down (upper part) and spin up (lower part) for $x=0.1$, $0.3,0.5,0.7$, and 0.9 . The Fermi level is located at $E=0 \mathrm{eV}$. In the both cases the contribution from majority spins (up) increases with the increase of the concentration. The shape of DOS near the Fermi level for minority spins (down) does not change significantly. The total density of states consists of contributions from La, $(\mathrm{Ce}, \mathrm{Pr})$ and $\mathrm{Pb}$. We have also plotted the local contribution to the total DOS for $\mathrm{La}_{0.5} \mathrm{Pr}_{0.5} \mathrm{~Pb}_{3}$ (Fig. 4) and $\mathrm{La}_{0.5} \mathrm{Ce}_{0.5} \mathrm{~Pb}_{3}$ (Fig. 5). In Fig. 4a and Fig. 5a the contributions from $\mathrm{La}(\mathrm{Pr} / \mathrm{Ce})$ and $\mathrm{Pb}$ are visualized. Figure $4 \mathrm{~b}-\mathrm{e}$ gives the contributions to DOS of $\operatorname{La}_{0.5} \operatorname{Pr}_{0.5} \mathrm{~Pb}_{3}$ : $\mathrm{La}\left(d_{3 / 2}, d_{5 / 2}, f_{5 / 2}, f_{5 / 7}\right)$ (Fig. 4b), $\operatorname{Pr}\left(f_{5 / 2}, f_{7 / 2}\right)$ (Fig. 4c) and $\operatorname{Pb}\left(s, p_{1 / 2}, p_{3 / 2}, d_{3 / 2}\right)$ (Fig. 4d). Similar results are presented for $\mathrm{La}_{0.5} \mathrm{Ce}_{0.5} \mathrm{~Pb}_{3}$ in Fig. 5. Figure 5a gives the total contribution from La, $\mathrm{Ce}$ and $\mathrm{Pb}$ atoms, however Fig. 5b and $5 \mathrm{c}$ have shown the part of the densities of states from La $(d, f)$ and Ce $(d, f)$ states, respectively. The contributions from lead are the similar as presented in Fig. $4 \mathrm{~d}$.

The dominated part to the DOS at the Fermi energy comes from $\mathrm{Ce}(\mathrm{Pr}) f_{5 / 2}$ states. The contribution from $\mathrm{Ce}(\operatorname{Pr}) f_{7 / 2}$ is about twice lower. The densities of states 

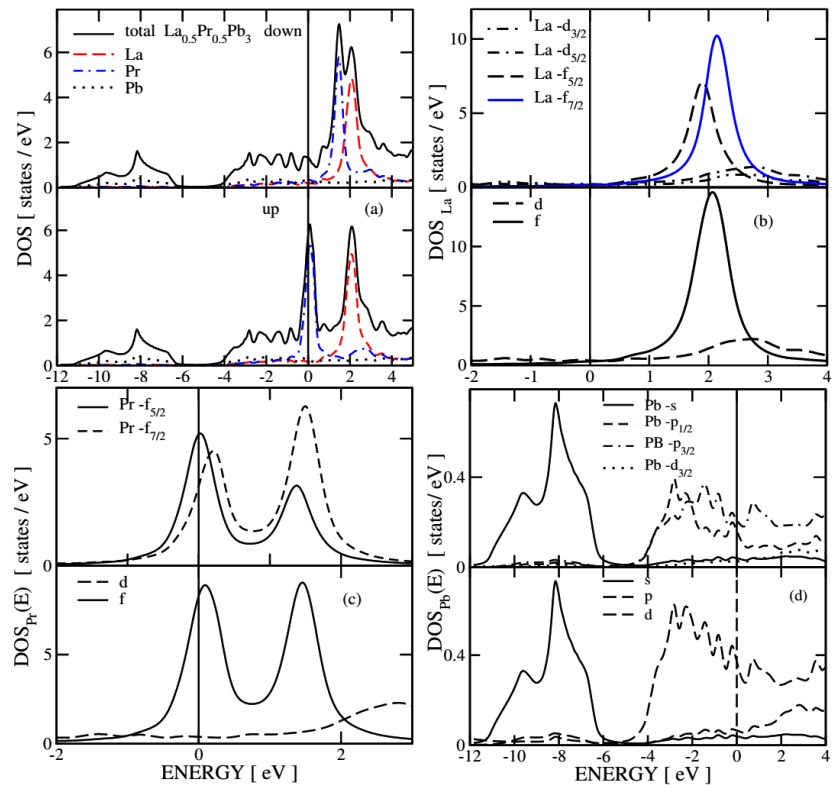

Fig. 4. Partial densities of states for $\mathrm{La}_{0.5} \operatorname{Pr}_{0.5} \mathrm{~Pb}_{3}$. Contributions from La, $\mathrm{Pr}$ and $\mathrm{Pb}$ (a), La (b), Pr (c), $\mathrm{Pb}(\mathrm{d})$.

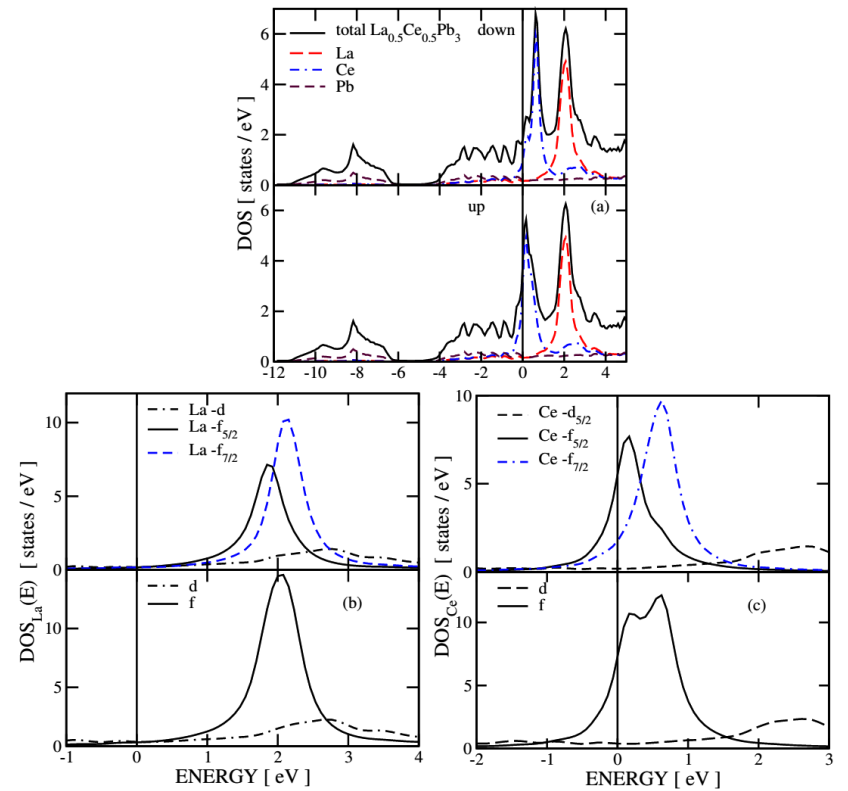

Fig. 5. Partial densities of states for $\mathrm{La}_{0.5} \mathrm{Ce}_{0.5} \mathrm{~Pb}_{3}$ Contributions from $\mathrm{La}, \mathrm{Ce}$ and $\mathrm{Pb}(\mathrm{a})$, La (b), Ce (c).

at the Fermi energy from $d$ states of $\mathrm{La}$ and $\mathrm{Ce}(\mathrm{Pr})$ are also small. The peak from La atom is located near $2 \mathrm{eV}$ above the Fermi level and we observed a small hybridization of La $f$ states and $\mathrm{Ce}(\operatorname{Pr}) f$ states around $E_{\mathrm{F}}$. In the total density of states of $\mathrm{REPb}_{3}$ the lower peak between $-12<E<-6 \mathrm{eV}$ presents the $\mathrm{Pb} s$ states and peaks between $-5<E<0 \mathrm{eV}$ give the contribution from $\mathrm{Pb} p$ states.

The dependence of density of states at the Fermi level $N\left(E_{\mathrm{F}}\right)$ on the concentration for magnetic $\mathrm{La}_{1-x} \mathrm{Ce}_{x} \mathrm{~Pb}_{3}$

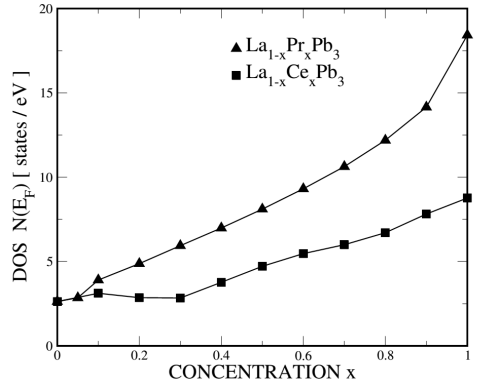

Fig. 6. The dependence of the density of states at the Fermi level $N\left(E_{\mathrm{F}}\right)$ on the concentration $x$ for $\mathrm{La}_{1-x} \mathrm{Ce}_{x} \mathrm{~Pb}_{3}$ (circle) and $\mathrm{La}_{1-x} \mathrm{Pr}_{x} \mathrm{~Pb}_{3}$ (triangle) compounds.

(squares) and $\mathrm{La}_{1-x} \mathrm{Pr}_{x} \mathrm{~Pb}_{3}$ (triangles down) is presented in Fig. 6. For $\operatorname{La}_{1-x} \operatorname{Pr}_{x} \mathrm{~Pb}_{3}$ the dependence of $N\left(E_{\mathrm{F}}\right)$ up to $x=0.3$ is almost constant and then increases. For $\mathrm{La}_{1-x} \mathrm{Ce}_{x} \mathrm{~Pb}_{3}$ we observe the increase of $N\left(E_{\mathrm{F}}\right)$ for $x>0.1$.

\subsection{The magnetic properties}

The change of the spin and orbital magnetic moments is plotted in Fig. 7 for $\mathrm{La}_{1-x} \mathrm{Ce}_{x} \mathrm{~Pb}_{3}$ and $\mathrm{La}_{1-x} \mathrm{Pr}_{x} \mathrm{~Pb}_{3}$ alloys, respectively. The spin magnetic moment of $\mathrm{La}_{1-x} \mathrm{Ce}_{x} \mathrm{~Pb}_{3}$ (circles) increases with increase of concen-

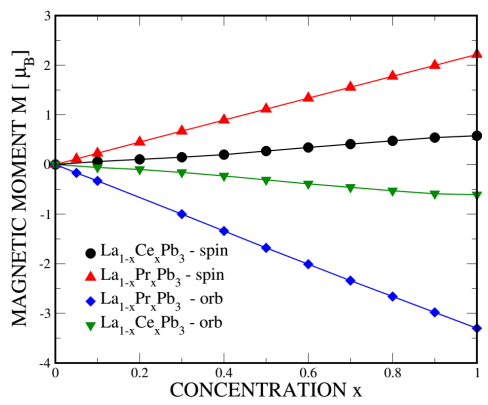

Fig. 7. The dependence of the spin and orbital magnetic moment on the concentration $x$ for $\mathrm{La}_{1-x} \mathrm{Ce}_{x} \mathrm{~Pb}_{3}$ and $\mathrm{La}_{1-x} \mathrm{Pr}_{x} \mathrm{~Pb}_{3}$ compounds.

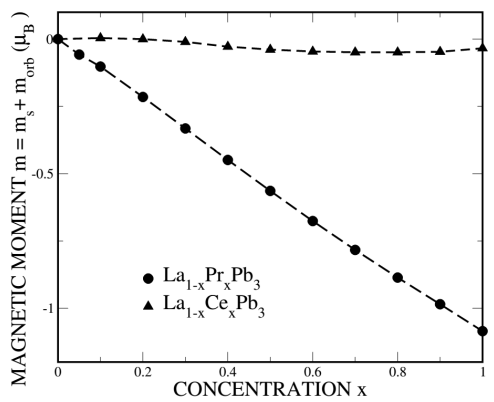

Fig. 8. The dependence of the total magnetic moment on the concentration $x$ for $\mathrm{La}_{1-x} \mathrm{Ce}_{x} \mathrm{~Pb}_{3}$ and $\mathrm{La}_{1-x} \operatorname{Pr}_{x} \mathrm{~Pb}_{3}$ compounds. 
tration $x$, however the orbital contribution decreases and the total magnetic moment (spin plus orbital) (triangles) in Fig. 8 is almost constant. In the case of $\mathrm{La}_{1-x} \mathrm{Pr}_{x} \mathrm{~Pb}_{3}$ the spin magnetic moment (triangles up) (Fig. 7) increases linearly but the orbital contribution decreases (diamonds). The total magnetic moment (circles) decreases with increase of concentration in Fig. 8.

\section{Conclusions}

The $a b$ initio band calculations using SPR-KKR-CPA $[18,19]$ indicate that the substitution of La atom by Ce or Pr changes the band structure near the Fermi level. We observe a small hybridization between $4 f$ states of $\mathrm{Ce}(\mathrm{Pr})$ and $\mathrm{Pb} d$ states. The values of the $N\left(E_{\mathrm{F}}\right)$ for the ordered $\mathrm{LaPb}_{3}, \mathrm{CePb}_{3}$ and $\mathrm{PrPb}_{3}$ are similar to those obtained by other $a b$ initio methods $[2,17]$ and they give the smaller value of $\gamma$ coefficient than observed in the experiments. The calculations were performed for magnetic $\mathrm{La}_{1-x} \mathrm{Ce}_{x} \mathrm{~Pb}_{3}$ and $\mathrm{La}_{1-x} \mathrm{Pr}_{x} \mathrm{~Pb}_{3}$ alloys for the whole range of concentration. The dominated contributions to the density of states at the Fermi level give $4 f_{5 / 2}$ states of Ce or Pr. The spin magnetic moment increases with the increase of the concentration of $\mathrm{Ce}$ or $\mathrm{Pr}$, but the total magnetic moment in the case of $\mathrm{La}_{1-x} \operatorname{Pr}_{x} \mathrm{~Pb}_{3}$ decreases when $x$ increases (Fig. 8).

\section{Acknowledgments}

This work was supported by the National Science Centre (Poland) through grant No. DEC-2011/01/B/ST3/ 02212 .

\section{References}

[1] L.B. Welsh, C.L. Wiley, F.Y. Fradin, Phys. Rev. B 11, 4156 (1975).

[2] P. Strange, B.L. Gyorffy, J. Phys. F, Metal Phys. 16, 2139 (1986).

[3] J.C. Arcas Soberino, J.J. Rieger, E.-W. Scheidt, G.R. Stewart, Phys. Rev. B 51, 11469 (1995).

[4] J.E. Han, M. Alouani, D.L. Cox, Phys. Rev. Lett. 78, 939 (1997).
[5] Z. Kletowski, R. Fabrowski, P. Slawinski, Z. Henkie, J. Magn. Magn. Mater. 166, 361 (1997).

[6] D. Aoki, Y. Katayama, R. Settai, Y. Inada, Y. Onuki, H. Harima, Z. Kletowski, J. Phys. Soc. Jpn. 66, 3988 (1997).

[7] T. Ebihara, K. Koizumi, S. Uji, C. Terakura, H. Suzuki, H. Kitazawa, G. Kido, Phys. Rev. B 61, 2513 (2000).

[8] T. Kawae, M. Shimogai, M. Mito, K. Takeda, H. Ishii, T. Kitai, Phys. Rev. B 65, 012409 (2001).

[9] M. Endo, N. Kimura, A. Ochiai, H. Aoki, Acta Phys. Pol. B 34, 1027 (2003).

[10] T. Kawae, K. Kinoshita, Y. Nakai, N. Tateiwa, K. Takeda, H.S. Suzuki, T. Kitai, Phys. Rev. Lett. 96, 027210 (2006).

[11] T. Onimaru, T. Sakakibara, N. Aso, H. Yoshizawa, H.S. Suzuki, T. Takeuchi, Phys. Rev. Lett. 94, 197201 (2005).

[12] T. Morie, T. Onimaru, Y. Karaki, T. Sakakibara, J. Custers, H.S. Suzuki, J. Phys. Soc. Jpn. 75S, 183 (2006).

[13] T.U. Ito, W. Higemoto, K. Ohishi, R.H. Heffner, N. Nishida, Y. Aoki, T. Onimaru, H.S. Suzuki, J. Magn. Magn. Mater. 310, 743 (2007).

[14] Y. Tokunaga, H.S. Suzuki, H. Sakai, H. Chodo, S. Kambe, H. Yasuoka, Y. Homma, D. Aoki, Y. Shiokawa, J. Phys., Conf. Ser. 150, 042211 (2009).

[15] T. Isshiki, N. Kimura, H. Aoki, H.S. Suzuki, J. Phys. Soc. Jpn. 80SA, SA073 (2011).

[16] Y. Sato, S. Makiyama, H. Morodomi, Y. Inagaki, T. Kawase, H.S. Suzuki, T. Onimaru, J. Phys., Conf. Ser. 391, 012060 (2012).

[17] Swetarekha Ram, V. Kanchana, A. Svan, S.B. Dugdale, N.E. Christensen, J. Phys., Condens. Matter 25, 155501 (2013).

[18] The Munich SPR-KKR package, version 6.3, H. Ebert et al., http: //ebert.cup.uni-muenchen.de/SPRKKR .

[19] H. Ebert, D. Kodderitzch, J. Minar, Rep. Prog. Phys. 74, 096501 (2011).

[20] P.J. Perdew, Y. Wang, Phys. Rev. B 45, 13244 (1992). 